Fecha de recepción: junio 2020

Fecha de aceptación: agosto 2020

Versión final: septiembre 2020

\section{A política das situações de projeto: uma investigação teórica em torno do Plano de Metas brasileiro}

Felipe Kaizer ${ }^{(1)}$

Resumo: No debate sobre design e política, o design figura em geral como instrumento da política. Nesse sentido, o design é subordinado a interesses alheios, sejam eles democráticos ou não. Logo, para que se revele sua dimensão política mais própria, é necessária outra concepção de design. Neste artigo, seguindo as teorias acumuladas desde os anos 1960, o design é considerado um processo. Como designing, ele é praticado não apenas por designers profissionais, mas por um conjunto de agentes, com responsabilidades e capacidades diversas. Esses agentes convergem em torno de um problema e dão origem a uma situação de projeto, fundamental ao processo de design. Pelo modo como tal situação articula os agentes em torno da produção de um futuro comum, revela-se sua natureza eminentemente política. O Plano de Metas do governo brasileiro entre 1956 e 1961 apresenta um caso excepcional de situação de projeto, na medida em que reorganiza agentes públicos e privados em uma administração paralela com o intuito de efetivar o Plano. Contornando a oposição do status quo político e a burocracia estatal, a estratégia organizacional de Juscelino Kubitschek possibilita de fato o cumprimento das promessas de campanha em prol do desenvolvimento nacional. Por fim, o estudo desse caso sob uma perspectiva teórica renovada reforça a existência de um campo do saber-e-fazer do design.

Palavras chave: Teoria do design - planejamento - Teoria organizacional - Administração - História política - Brasil.

[Resumos em espanhol e inglês nas páginas 79-80]

(1) Doutorando qualificado em 2018 no Programa de Pós-Graduação da Escola Superior de Desenho Industrial na Universidade Estadual do Rio de Janeiro (PPD-ESDI/UERJ). Graduado em Desenho Industrial pela Pontifícia Universidade Católica do Rio de Janeiro (PUC-Rio, 2002-2006). Contato: fk@felipekaizer.com 


\section{Introdução}

A palavra "democracia" tem sido repetida a propósito das últimas eleições ao redor do mundo. Em especial, a chegada de Donald Trump à presidência dos Estados Unidos em 2017 despertou entre intelectuais e analistas políticos a preocupação com a sobrevivência da ordem democrática. How Democracy Ends (Runciman, 2018), How Democracies Die (Levitsky \& Ziblatt, 2018) e Can Democracy Survive Global Capitalism? (Kuttner, 2018) são alguns dos títulos que manifestam essa preocupação. Os autores alertam respectivamente para: o risco da vitória de líderes extremistas, capazes de subverter o processo democrático que os levou ao poder; a crescente ineficácia das atuais instituições para enfrentar as ameaças do século XXI (aquecimento global, disrupção tecnológica etc.); e a quebra do contrato social na era da globalização e da ascensão do populismo de direita. De acordo com essas visões, a questão da democracia não se restringe a eleições e regimentos, mas se conecta com os grandes desafios da humanidade.

Diante dessa ordem de problemas, os designers perguntam-se: o que o design pode fazer? As respostas variam: de projetos ad hoc voltados para comunidades marginalizadas à consolidação em regimes democráticos de políticas públicas de incentivo à prática, à formação $\mathrm{e}$ à pesquisa em design. Mas a própria pergunta sugere uma reflexão: que "design" os designers têm em mente? Ao questionar seu papel social e político, eles especulam sobre os novos meios de aplicar seus conhecimentos e suas habilidades em prol de uma determinada causa, seja ela a manutenção da ordem democrática, seja a preservação do meio ambiente. Nisso, porém, eles assemelham-se a quaisquer outros profissionais que desenvolvem uma consciência ética e moral. Mesmo reconhecendo a gravidade do momento histórico, sua pergunta circunscreve problemas de ordem social e política a problemas de classe profissional. Em outras palavras, os designers pensam a própria prática em termos de meio e finalidade. Para eles, a prática é justificável se a causa final é justa. O design é "democrático" ou "social" se serve à causa da democracia ou da justiça social. Trata-se de uma lógica que procura acima de tudo legitimar a existência da classe. Não obstante, a escala e a complexidade dos problemas contemporâneos ignoram divisões profissionais e não se conformam às competências de nenhum campo. Logo, o modo de lidar com problemas dessa natureza passa, entre outras coisas, pela coordenação de múltiplas capacidades.

Propomo-nos então a tratar da atividade, do designing, e não dos designers. No contexto do design, o que está em jogo é o poder e o modo pelo qual o projetar muda o status quo. É nesse sentido que procuramos identificar a natureza política da prática de projeto.

\section{Design como ferramenta}

A confusão entre problemas de ordem profissional e problemas de ordem política e social vem à tona com o livro de Victor Papanek, publicado em 1971 nos Estados Unidos: Design for the Real World: Human Ecology and Social Change. Segundo o autor, nada fora publicado até então a respeito da responsabilidade do designer (Papanek, 1985, pp. ixxiv). Para ele, essa responsabilidade remete ao potencial "nocivo" da profissão, dado que 
o design tornou-se "a mais poderosa ferramenta com a qual o homem dá forma às suas ferramentas e ao meio ambiente (e, por extensão, à sociedade e a si mesmo)". Consequentemente, o poder atribuído ao design "demanda uma grande responsabilidade social e moral do designer" e demanda dos "designers engajados social e moralmente" um "maior entendimento das pessoas". É em nome das pessoas, em nome das "verdadeiras necessidades dos homens", que atuam aqueles "que praticam design". Essa concepção supõe uma desigualdade fundamental entre agentes sociais, na medida em que uns têm mais poder e responsabilidade do que outros. Nesses termos, há uma conexão direta entre uma concepção do design como ferramenta e o estabelecimento de uma hierarquia social, marcada pela ascendência dos profissionais de projeto. Não obstante, Papanek nega essa ideia:

Todos os homens são designers. Tudo que nós fazemos, quase o tempo todo, é design, pois o projetar está na base de toda atividade humana. O planejamento e a padronização de qualquer ato na direção de um fim desejável e previsível constituem o processo de design. Qualquer tentativa de separar o design, de torná-lo algo em si, trabalha contra o fato de que o projetar é a matriz primária subjacente à vida ${ }^{1}$ (Papanek, 1985, p. 3).

À primeira vista parece ocorrer uma suspensão da divisão entre os designers e os outros agentes sociais. No entanto, considerando a generalidade da definição, dá-se outra coisa: a classe profissional dos designers expande-se a ponto de abarcar "todos os homens", isto é, qualquer um "que pratica design". Isso resulta da confusão entre atividade e profissão, resultante de uma concepção do design como ferramenta. Como tal, o design pode ser utilizado por qualquer um, e qualquer um que o utiliza torna-se um designer.

É fácil perceber como o argumento de Papanek adapta-se ao contexto social e político: "Todas as nossas ferramentas, objetos, artefatos, mecanismos de transporte ou edifícios têm consequências que alcançam as mais diversas áreas, como a política, a saúde, a renda e a biosfera" (Ibid., pp. 23-24). Em outras palavras, a relevância política e social do design deriva da abrangência das suas consequências. Em nenhum momento, porém, ilumina-se como essa ferramenta funciona. Em suma, Papanek privilegia os efeitos materiais sobre o modus operandi do design. O designing ele mesmo permanece obscuro.

Dando continuidade ao argumento, Tony Fry atualiza a pergunta sobre o papel social dos designers, dessa vez "em face do estado insustentável do mundo" (Fry, 2011, "Preface"). Sua resposta baseia-se igualmente na "capacidade potencial" do design de ser "um instrumento da mudança" do status quo. Fry defende uma maneira de pensar sobre "design, projeto e política" que possa superar a atual condição de insustentabilidade. Considerando que a democracia, como "política institucionalizada", tornou-se "incapaz de garantir a sustentabilidade [Sustainment]", o design torna-se, para ele, "um agente político vital". Segundo Fry, a democracia "deve ser superada e substituída por uma forma superior de política", pois, entre outras coisas, faltam às instituições democráticas "o noûs e a tékhnē apropriados". É nesse sentido que o design e o projeto tornam-se centrais no desenvolvimento de "uma nova forma do político". A nova concepção de político, no entanto, remete ainda às consequências do design como ferramenta: 
Em um mundo de urbanização acelerada, pressões demográficas crescentes, insustentabilidade estrutural, somadas a probabilidade de maiores conflitos sobre os recursos naturais e uma enorme explosão de refugiados ambientais devido às mudanças climáticas, a relação entre o design e o político se tornará mais evidente e mais importante. Face a essa situação, o design deve se tornar aberta e proativamente político. O design tem de se tornar uma política. Para que o design se politize, ele tem de confrontar diretamente a política (Ibid., "Introduction").

Em suma, Fry propõe que se faça um outro uso da ferramenta do design: um que confronte a política institucionalizada. No entanto, mesmo ausente a preocupação com a classe profissional ${ }^{2}$, continua a vigorar uma concepção da atividade em termos de meio e finalidade. A despeito do novo papel de um design "politizado", o campo do "design" e o campo do "político" permanecem separados. Como ferramenta, o design torna-se "uma política" a depender das consequências que tem. Mas, como tal, ele pode ser igualmente "vital" ou "nocivo". Em outras palavras, o design não é político em si; ele apenas tem um uso político. No contexto latino-americano, Gui Bonsiepe é um dos principais defensores dessa tese. Seu argumento é de que, como disciplina que "enfoca o caráter operacional dos artefatos materiais e semióticos" (Bonsiepe, 2012, p. 19), o design cumpre um papel determinante na superação do atraso socioeconômico dos países chamados "periféricos", entre os quais se inclui o Brasil. A própria divisão do mundo em Centro e Periferia deriva de uma contribuição latino-americana à teoria econômica, identificada como Teoria da Dependência (Ibid., p. 64). Para Bonsiepe, o design praticado na Periferia tem o poder de retirar esses países da condição de exportadores de commodities e importadores de produtos industriais (Ibid., p. 23). Em outras palavras, dentro de uma divisão internacional do trabalho, os "esforços locais de design" justificam-se na medida em que buscam "reforçar a autonomia" ou "reduzir a heteronomia" dos países periféricos.

A "redução da heteronomia" é ela mesma a definição de democracia dada pelo autor (Id., 2011, pp. 20-21). Ela significa a "participação dos dominados, para criar um espaço de autodeterminação", e integra uma concepção maior de "humanismo", que, no caso do design, manifesta-se na "atenção [...] aos excluídos, aos discriminados". Contudo, a relação entre design e democracia continua a ser contingente, isto é, não necessária. Como ferramenta, o design pode servir igualmente bem a propósitos antidemocráticos, como lembra o próprio Bonsiepe:

Eu não digo que o design é sempre um instrumento de dominação. Se é usado como instrumento de dominação depende de interesses político-econômicos. Design -assim como a ciência-pode ser uma ferramenta de interesses hegemônicos, mas não necessariamente é (Ibid., p. 29).

Do mesmo modo, o design não é necessariamente um instrumento de redução da heteronomia. Do ponto de vista teórico, a concepção do design como ferramenta implica basicamente sua independência em relação à política, isto é, àquele "domínio onde os membros de uma sociedade discutem e decidem o tipo de sociedade em que querem viver” (Id., p. 
37). Essa independência, porém, não equivale à "autonomia" defendida por Bonsiepe para os países, pois um campo autônomo ou independente significa simplesmente um campo que não depende dos parâmetros de outros campos para se determinar. Em outras palavras, o design como "instrumento de dominação" é tão justificável quanto o design que procura reduzir a dominação, o que o torna essencialmente apolítico. A validade do primeiro ou do segundo caso depende de "interesses político-econômicos", vindos de outro lugar. Ao contrário do que parece inicialmente, a independência do campo do design em relação ao campo da política leva à subordinação dos designers aos interesses de outros agentes, pois resta-lhes o papel de executores de decisões tomadas alhures, tenham elas um sentido democrático ou não. A concepção instrumental do design implica afinal a instrumentalização daqueles "que praticam design". Por fim, a prática do design encontra-se ela mesma em uma condição de heteronomia.

\section{Design como processo}

Uma relação mais íntima entre design e política exige uma outra concepção de design, não mais limitada à utilidade ou ao perigo das ferramentas.

Antes de Victor Papanek começar a escrever o seu livro, um grupo de profissionais de projeto reúne-se em Londres em uma conferência sobre "os métodos sistemáticos e intuitivos da engenharia, do desenho industrial, da arquitetura e da comunicação"3 (Cross, 1984, p. vii). O Movimento Design Methods, lançado em 1962 com essa conferência, promove uma nova concepção de design, na medida em que promove o estudo geral do método de projeto. Sua preocupação fundamental é com "o modo como o projetar é e pode ser conduzido", independentemente das particularidades daquilo que é projetado. A mesma preocupação com a metodologia de projeto emerge também na Hochschule für Gestaltung em Ulm, na Alemanha. Especialmente a partir de 1958, a escola procura "uma base metodológica sólida para o trabalho do design” (Lindinger, 1991, p. 11). Chama a atenção, em ambos os casos, o novo estatuto das consequências da prática do design: em uma teoria sobre o como projetar, resta àquilo que é projetado a condição de problema a ser resolvido. Em 1969, um teórico da administração chamado Herbert Simon contribui decisivamente para essa nova concepção de design com o livro The Sciences of the Artificial. De acordo com Simon, há um campo das "ciências artificiais", contraposto àquele das ciências naturais (Simon, 1996). Enquanto as ciências naturais tratam de "como as coisas são", as ciências do artificial tratam de "como as coisas podem ser - em uma palavra, com o design" (Ibid., p. xii). O design procura então "conceber artefatos para atingir objetivos" (Ibid., p. 114), sem se confundir com os próprios artefatos. É proposta uma "ciência do design", isto é, "um corpo de doutrina intelectualmente firme, analítica, parcialmente formalizável, parcialmente empírica, e ensinável sobre o processo de design” (Ibid., p. 113), e tal processo encontra-se no cerne do "estudo próprio" do artificial.

A teoria de Simon baseia-se em um modelo computacional do comportamento humano. Ela procura compreender como os seres humanos resolvem problemas, de modo que seja possível desenvolver uma inteligência artificial capaz de fazer o mesmo. Assim como 
o Design Methods, Simon considera o processo de design um processo de resolução de problemas. Para ele, os problemas de design são de um tipo que excede as capacidades da "inteligência como computação" (Simon, 1996, p. 23). Nesse sentido, os problemas exigem do designer uma atitude aproximativa, que produza soluções "satisfatórias" em vez de ótimas (Id., p. 119). Pouco depois da publicação do livro de Simon, a dificuldade intrínseca à resolução de problemas de design é radicalizada com o emprego do conceito de "problema traiçoeiro" (wicked problem). De acordo com o teórico do planejamento Horst Rittel, os problemas de design não são problemas "domesticados" e, consequentemente, não são passíveis de uma resolução mecânica (Rittel, 2010a). Em linhas gerais, os problemas traiçoeiros não permitem uma formulação definitiva, não oferecem uma regra de parada do processo, nem têm um conjunto fechado de soluções ou operações válidas. Diante desse impasse, Rittel é levado mais tarde a investigar o tipo de "raciocinar" que capacita os designers a lidarem com esses problemas (Id., 2010b).

Na sequência das teorias de resolução de problemas, o teórico Richard Buchanan propõe nos anos 1980 "uma nova concepção da disciplina como uma empreitada humanística, reconhecendo a dimensão inerentemente retórica de todo pensamento de design" (Buchanan, 1995, p. 24). Para Buchanan, a retórica refere-se "à influência dos designers e ao efeito do design sobre um público de consumidores ou sobre o todo da sociedade", na medida em que os designers "fazem objetos para falar com vozes particulares, imbuindoos de qualidades pessoais” (Id., 1989, pp. 91-105). A retórica nessa teoria não se restringe à oratória ou a uma arte das palavras, mas inclui "uma retórica das coisas". Essa concepção está de acordo com a antiga rhētorikế, que é simplesmente um saber "discernir os meios de persuasão mais pertinentes a cada caso" e não possui um objeto de estudo próprio (Aristóteles, 2005, p. 94). Buchanan define o design como um campo cuja matéria é fundamentalmente indeterminada, e assim transforma a colocação inicial de Herbert Simon:

O pressuposto é que o design tem uma matéria fixa ou determinada, que é dada ao designer do mesmo modo que a matéria da natureza é dada ao cientista. No entanto, a matéria do design não é algo dado. Ela é criada através das atividades de invenção e planejamento, ou através de qualquer outra metodologia ou procedimento que o designer julgue útil à caracterização do seu trabalho. [...] Em outras palavras, há uma determinação na ciência natural, e o objetivo da investigação é o conhecimento das propriedades e a previsibilidade dos processos.

Não há determinação similar na atividade de projeto. A matéria do design é radicalmente indeterminada [...] (Buchanan, 1995, p. 24).

Logo, o processo de design é pensado como a passagem de um estado inicial de indeterminação para um estado determinado. Para Buchanan, os designers "começam com uma situação de incerteza e possibilidade" e, ao final, "apresentam um produto que atende às necessidades da situação, dando unidade e encerrando aquilo que era incerto e determinado" (Id., 2005, p. 7). Sua referência é o conceito de investigação, de John Dewey. A investigação "é a transformação controlada e dirigida de uma situação indeterminada em uma determinada” (Dewey, 1938, p. 104). Nesses termos, o design é definido como "uma 
forma de interagir como o mundo de modo a investigar o ambiente" e "o que significa ser humano" na era atual (Buchanan, 2005, p. 5).

Como investigação, o design é "um processo contínuo", pois a investigação não se "assenta" definitivamente em uma situação determinada (Dewey, 1938, pp. 6-8). Isso significa que o design "é mais do que uma atividade de resolução de problemas, e mais do que uma coleção de métodos e técnicas de pesquisa e prática" (Buchanan, 2005, p. 4). Ele alimenta-se constantemente de novas necessidades e novas possibilidades. Consequentemente, como campo de investigação, o design ocupa-se acima de tudo com o saber envolvido nesse processo. Esse saber versa não apenas sobre a natureza dos produtos e suas consequências para a vida individual e coletiva, mas principalmente sobre $o$ modo como os produtos vem a ser (Id., 1999, p. 16).

Após Simon e Buchanan, é possível compreender as práticas atuais do design no interior das organizações. As produções organizadas recentemente por Richard Boland Jr. e Fred Collopy (Managing as Designing, 2004), e Sabine Junginger e Jürgen Faust (Designing Business and Management, 2016) baseiam-se na ideia de que administradores e policy makers também "praticam design", bem como uma miríade de outros profissionais. Segundo essa concepção, o processo de design é necessariamente transdisciplinar, dada a natureza traiçoeira dos problemas que enfrenta. No limite, o design é considerado ele mesmo uma "transdisciplina" (Buchanan, 1999, p. 7).

Finalmente, a concepção do design como processo permite-nos observar fenômenos antes inexistentes na literatura especializada. O exemplo brasileiro do Plano de Metas de Juscelino Kubitschek nos anos 1950 é um desses casos, em que se revela potencialmente o processo de designing independentemente daquilo que é designed. Por meio dele, procuramos também revelar a dimensão política, intrínseca a esse processo.

\section{O caso do Plano de Metas}

Com o lema "50 anos em 5", a campanha de Juscelino Kubitschek aponta para a superação da condição subdesenvolvida do Brasil no cenário internacional e, em âmbito nacional, representa por si só uma novidade, pois se fundamenta em questões de planejamento. Ao que tudo indica, sua decisão de planejar responde a "novas fontes de demandas e novas exigências de apoio" advindas do crescimento do eleitorado, em especial do eleitorado urbano, a partir de 1945 (Lafer, 2002, pp. 29-39). Em um período marcado pelo populismo, a candidatura de Kubitschek equivale afinal a uma "política de compromisso e de conciliação" entre os interesses das elites e das massas, considerando a continuidade do processo de ampliação das oportunidades de emprego (Ibid., pp. 43-62).

Juscelino Kubitschek foi eleito em 1955 com um Programa ou Plano de Metas de Desenvolvimento que abarcava cerca de um quarto da economia nacional, visando o crescimento econômico por meio da substituição de importações e da criação de infraestruturas. Em suma, o Plano propunha a intervenção do Estado na economia por meio da manipulação de incentivos (Ibid., p. 48). Ele insere-se em um processo maior de industrialização e modernização do país, iniciado na Primeira República e consolidado após a chegada de 
Getulio Vargas ao poder em 1930. Não obstante, o Plano de Metas "pode ser considerado a primeira experiência efetivamente posta em prática de planejamento governamental no Brasil" (Id., 2003, p. 30).

Para os nossos propósitos, destaca-se a importância do planejar. Como "conceito político", ele representa principalmente "a visão e as expectativas de um futuro" no qual confiam diferentes grupos sociais (Id., 2002, p. 49). A decisão de planejar consiste em "uma tentativa de reduzir a incerteza sobre as novas políticas", dado o conflito em potencial entre tais grupos. De fato, o Plano de Metas procurou manter "o controle sobre as áreas de incerteza" -isto é, sobre a oferta de tecnologia e recursos financeiros-, de modo a ganhar mais poder sobre os "demais componentes do sistema", isto é, sobre aqueles que tinham participação na política (Ibid., p. 88). Contudo, tal controle não foi atingido por meio de um único ato de planejamento. Em suma, o Plano de Metas foi um planejamento contínuo, e não "um plano global e rígido". Na verdade, trata-se de um projeto, isto é, um processo que inclui tanto a elaboração do "plano em si" quanto a "implementação do plano" (Ibid., pp. 2548). Seus objetivos eram "continuamente testados e revistos durante a aplicação do plano, através do método de aproximações sucessivas" (Ibid., p. 52), e o Plano ajustava-se continuamente através de um mecanismo de "retroalimentação" (Ibid., p. 61). Esse processo de "mudança contínua" está de acordo com o próprio sistema político onde o Plano se insere, uma vez que tal sistema "se modifica na medida em que funciona e opera" (Ibid., p. 50). Logo, trata-se menos do controle do que da produção continuada de uma nova situação política e social.

Nem mesmo o "plano em si" foi concebido inteiramente de uma vez. Ele teve início com "um grupo pequeno, fluido, sem uma atividade permanente", que tinha como objetivo reunir informações e dados para a campanha (Lopes, 1991, pp. 165-167). Em 1955, o trabalho do grupo foi publicado sob o título de Diretrizes gerais do Plano Nacional de Desenvolvimento. Trata-se de uma publicação sintética, sem definição específica dos grandes projetos, com a função primordial de transmitir "aos banqueiros, a todo mundo" o compromisso de Kubitschek com o controle da inflação por meio de investimentos graduais (Ibid., p. 183). Mas a publicação não contém qualquer análise macroeconômica. $\mathrm{Na}$ verdade, o programa só ganhou nitidez após as eleições, quando Lucas Lopes, o cabeça do grupo, após um período de discussão com o economista Roberto Campos, mobilizou uma equipe do Banco Nacional de Desenvolvimento Econômico (BNDE) para quantificar as metas. As trinta metas foram definidas "praticamente na época da posse" (Ibid., p. 169). A trigésima meta, por exemplo, foi definida na véspera da divulgação do plano, e apenas por insistência do novo ministro da Educação (Ibid., p. 201).

As metas foram finalmente divulgadas em uma reunião no dia seguinte à posse. Na mesma ocasião, Kubitschek criou um mecanismo dedicado à execução do Plano: o Conselho do Desenvolvimento Econômico. O Conselho é considerado uma "estratégia administrativa", diante do baixo grau de racionalidade e eficiência da burocracia federal resultante da prática histórica do clientelismo (Lafer, 2002, p. 65). Para todos os efeitos, ele faz parte de uma "administração paralela", criada para viabilizar o Plano. Diferentemente de outros conselhos, "que se reuniam uma vez por mês para fazer discursos", ele funcionava como "uma secretaria executiva capaz de formular programas objetivos" (Lopes, 1991, p. 170). Sua função não era simplesmente planejar as metas ${ }^{4}$ - ele era uma "plataforma" a partir da 
qual as decisões eram "postas em execução diretamente". Seu formato, portanto, respondia ao imperativo de efetivação e revisão constante do plano. Lucas Lopes relata:

O Conselho do Desenvolvimento nunca teve uma estrutura muito grande. [...] poderia ter sido chamado de Comitê do Plano. Através dele, Juscelino quis centralizar algumas decisões sem atingir, ou sem chocar os seus ministros. Muitas vezes, quando avançava uma ideia ou um programa, Juscelino poderia estar atropelando um ministro qualquer, se não agisse de uma forma elegante. E ele resolvia o problema através de um mecanismo de consulta ao Conselho do Desenvolvimento [...] Convidava o ministro, seus assistentes, o Conselho do Desenvolvimento e o BNDE para trabalharem juntos. Desse modo, o conselho não teve formalismo. Não existem sequer atas de reunião do conselho, a não ser a primeira, que foi mais um press release (Lopes, 1991, p. 171).

Em um primeiro momento, integraram o Conselho os chefes das Casas Civil e Militar, o presidente do BNDE, o presidente do Banco do Brasil e alguns ministros. O que esses agentes tinham em comum era a experiência de projeto e planejamento (Lafer, 2002, pp. 54-55). Eram "todos técnicos de alto nível, experimentados não apenas em tentativas anteriores de planejamento como também em cargos políticos relevantes” (Ibid., p. 85). Alguns tinham passagem pela Comissão Mista Brasil-Estados Unidos ou pelo Governo do Estado de Minas Gerais, como o próprio Kubitschek. O Conselho não tinha presidente ou vice-presidente; apenas um secretário-geral. Ninguém assinava os documentos ou procurava ser dono do projeto; imperava sobretudo "uma preocupação grande de somar forças" (Lopes, 1991, pp. 174-175). A colaboração com outros órgãos, por sua vez, era facilitada pela coincidência de cargos: o secretário-geral era sempre o presidente do BNDE, assegurando assim "a coordenação entre a agência planejadora e sua principal fonte de recursos financeiros" (Lafer, 2002, p. 99). A coincidência evitava a demora com as consultas externas e contribuia para a uniformidade dos critérios aplicados (Ibid., p. 102). Kubitschek tinha em mente "um governo com uma certa participação de seus auxiliares, mas com uma grande concentração de decisões fundamentais" (Lopes, 1991, p. 171).

Há dúvidas, no entanto, a respeito da efetividade do Conselho do Desenvolvimento. Segundo Roberto Campos, o Conselho "nunca se operacionalizou" (Campos, 1994, pp. 299). O "órgão realmente ativo" era sua secretaria geral, chefiada por Lucas Lopes entre 1956 e 1958 e pelo próprio Campos entre 1958 e 1959. Lopes confirma esse fato, contrário ao relato supracitado, em depoimento à Maria Victoria de Mesquita Benevides em 1974:

[...] na realidade o Conselho do Desenvolvimento 'nunca existiu', ou seja, nunca foi operacional, até mesmo devido à extrema dificuldade de se reunir; se 'funcionou' de alguma maneira, pelo menos formalmente, deve-se ao fato de que eu acumulei a função de Secretário Executivo do Conselho com a de Presidente do BNDE [...] (Lopes apud Benevides, 1979, pp. 231-232).

Não obstante, o Conselho foi responsável pela formação de grupos especiais. Os chamados Grupos de Trabalho (GT) e Grupos Executivos (GE) foram peças-chave na administração 
paralela do governo. Os GT assessoravam e preparavam projetos de lei e regulamentação, e os GE concediam e manipulavam os incentivos necessários (Benevides, 1979, pp. 228230). A composição dos grupos incluia membros do Conselho do Desenvolvimento, de órgãos preexistentes da administração pública e agentes do setor privado. Alguns indivíduos participavam de mais de um grupo, o que garantia a concordância das análises e a coordenação das decisões. O secretário-geral do Conselho, por sua vez, funcionava como um "curinga", supervisionando diversos grupos (Campos, 1994, p. 321). Do mesmo modo, o BNDE- como principal instrumento de financiamento do Plano -formou equipes especiais, requisitando pessoal de outros setores da administração pública. De fato, no geral, a administração paralela do governo Kubitschek funcionou por meio da combinação de órgãos novos e preexistentes (Benevides, 1979, p. 224). Na medida em que rearranjava os agentes do poder público, ela buscava "a utilização ótima dos membros mais competentes do sistema", com vistas à implementação do Plano (Lafer, 2002, pp. 109-110). Ao final, a concentração de pessoal qualificado teve maior "eficiência global" do que a soma de "esforços individuais espalhados pelos diversos órgãos". Isso exigiu que o governo Kubitschek escolhesse a dedo as pessoas capazes de efetivar o Plano e criasse entre elas os laços necessários para tanto.

À primeira vista, a administração paralela não é “democrática”. Ela pode ser considerada "uma forma sub-reptícia de obter delegação de poderes negada pela Constituição" (Benevides, 1979, p. 252). Parte significativa do seu poder advém da coincidência de cargos e do círculo de relações pessoais. Além disso, não parece haver audiências públicas ou auditorias independentes durante o período do seu funcionamento. Ainda assim, é difícil imaginar a realização do Plano de Metas sem ela, visto que "uma reforma administrativa global" que permitisse a realização do Plano "seria politicamente impossível” (Lafer, 2002, pp. 84-85). Isso não significa que a administração paralela é "a melhor alternativa" ou "a única saída"; ela é apenas a opção "mais condizente com a lógica do sistema" e mais adequada "à personalidade do chefe do Executivo e à sua experiência anterior no governo de Minas Gerais". De toda forma, a estratégia de Kubitschek justifica-se politicamente em função do "objetivo último" do Plano, a saber, o aumento do "padrão de vida do povo" (Ibid., pp. 48-49). Em última instância, a legitimidade da administração depende da percepção de que a vitória de Kubitschek significa "a aceitação das teses e projetos enunciados no programa de desenvolvimento". Isso, porém, não elimina a tensão entre as massas e as elites: o governo Kubitschek encontra-se no centro de um "conflito entre as políticas que visavam a preservação do status quo e aquelas destinadas a modificar esse quadro" (Ibid., p. 81). Nesse sentido, o Plano de Metas representa afinal uma "ameaça" aos interesses conservadores.

Diante do obstáculo oferecido por esses interesses, a administração paralela de Kubitschek equivale a "um núcleo dinâmico, capacitado para assegurar a viabilidade de implementação do plano" (Ibid., p. 83). Em termos de racionalidade administrativa, ela deriva da avaliação da menor resistência provável à realização do plano (Ibid., p. 87). Em função do seu compromisso com a mudança efetiva das condições existentes, ela representa afinal a um parêntese dentro da estrutura burocrática, isto é, um espaço de decisão e execução de medidas contrárias às forças de manutenção do status quo. 
A despeito do seu propósito ou do seu sucesso, a administração paralela não responde aos anseios de uma democracia direta ou com maior participação popular. Logo, o seu sentido "político" tem possivelmente uma conotação pejorativa: refere-se aos jogos de poder circunscritos a uma classe política, facilitados pelo sistema de representação. Nesse sentido também, a administração paralela levanta questões a respeito do princípio constitucional da divisão dos poderes, que procura evitar tanto o autoritarismo quanto a instabilidade provocada por mudanças radicais. Isso porque, do ponto de vista da legitimidade concedida pelo voto, tanto as forças de transformação quanto as forças de preservação do status quo podem ser defendidas "em nome do povo". Porém, dependendo das características da campanha, é preciso igualmente que as forças eleitas para mudar se efetivem. Em outras palavras, a legitimidade do governo depende não apenas da maioria dos votos, mas também do seu compromisso em cumprir o prometido. Isso é especialmente verdadeiro no caso de uma candidatura baseada em um plano. Contudo, o planejamento não autoriza ações disruptivas; ao contrário, é por meio do planejar que o candidato propõe mudanças por meios explícitos e conciliatórios. Nesse outro sentido, o plano também é "político", considerando o modo como ele promove a mudança.

\section{A situação de projeto}

Há ainda um terceiro sentido de "político" no caso da administração paralela do governo Kubitschek. Ele refere-se ao espaço aberto por esse "grupo dinâmico", no qual todos procuram "somar forças" em torno de um mesmo projeto. A reunião dos agentes de projeto em grupos e conselhos interligados cria uma situação, dentro da qual suas ações têm efeito. A rigor, não se trata de um contexto isonômico, pois continuam a existir diferenças hierárquicas entre os seus membros. Não obstante, dos poucos relatos existentes ${ }^{5}$, é possível inferir que as ações no interior dessa administração não se dividem simplesmente entre comando e obediência. Kubitschek não parece ter criado o Conselho do Desenvolvimento ou os grupos especiais para ser "melhor obedecido". Ao contrário, tais arranjos possibilitam o livre compartilhamento de informações, impressões e experiências pessoais, para além das distinções hierárquicas.

Nesse sentido, o processo de projeto -incluindo a concepção inicial, execução e avaliação do plano- está intimamente ligado a uma situação de projeto: sem grupos dedicados, o mais provável é que o plano nunca se realizasse. A situação é algo que emerge do encontro dos agentes, sem que nenhum deles seja individualmente responsável por ela. É verdade que o presidente decreta a existência do Conselho; mas é a participação ativa e cotidiana dos membros da administração que cria de fato as condições de realização do projeto. Do contrário, o Conselho de Desenvolvimento poderia nomear mais um órgão inoperante da burocracia estatal. A situação cria-se e existe enquanto os agentes interagem, e desaparece assim que eles se separam. E ao desfazimento dos grupos dedicados ao projeto equivale $\mathrm{o}$ término do processo de projeto. Logo, a situação de projeto indica uma política intrínseca ao projetar, na medida em que enseja um projeto comum a partir de interesses, visões e poderes distintos. 
Essa concepção de político deve muito à teoria política de Hannah Arendt. Para Arendt, a política é feita de ação. Em linhas gerais, a ação arendtiana é uma atividade humana fundamental que se dá "diretamente entre os homens, sem a mediação das coisas ou da matéria” (Arendt, 2001, p. 15). Sua mediação mais própria são gestos e palavras intangíveis, que desaparecem e tendem ao esquecimento passado o "instante fugaz" (Ibid., p. 204). A ação ocorre "entre os homens", quando eles "agem e falam diretamente uns com os outros", e "só existe em sua efetivação" (Ibid., pp. 195-202).

Para Arendt, a ação é um processo. Mais do que isso, a ação "atua sobre um meio no qual toda reação se converte em reação em cadeia, e todo processo é causa de novos processos" (Ibid., p. 203). Em outras palavras, ela "atua sobre seres que também são capazes de agir", e a reação "é sempre uma nova ação com poder próprio de atingir e afetar os outros". Desse modo, a ação arendtiana configura uma "teia de relações", que existe "onde quer que os homens vivam juntos", e consiste basicamente na "esfera dos negócios humanos" (Ibid., pp. 195-196). É essa teia que "relaciona e interliga" os agentes em torno de "algo que interessa", isto é, algo que se coloca entre eles.

A "teia" é um nome para a situação que entrelaça os agentes, e dentro da qual suas ações têm efeito e sentido. Sugerimos que o conceito arendtiano de ação é compreensível apenas em relação a uma noção de situação. Melhor dizendo, as ações fundam uma situação ao mesmo tempo em que são fundamentadas por ela. No entanto, para que as ações sejam propriamente políticas, é preciso que os agentes estejam em condições iguais para agir. A igualdade é para Arendt a conditio sine qua non da ação política. Ela é fruto de um "fator igualador" que "não provém da natureza humana", mas da constituição de um corpo político (Ibid., p. 227). Historicamente, a igualdade política surge juntamente com a pólis (Ibid., p. 211). Como um corpo político, a pólis proporciona a "igualdade de desiguais", sem a qual não se pode agir livremente. Para Arendt, como para os gregos, a igualdade é "a própria essência da liberdade" (Ibid., p. 42), e a liberdade é a raison d'être da política. Trata-se da liberdade para dar início a "novos processos" e não da liberdade para agir a despeito dos outros. Logo, nessa concepção de político, a ação é incompatível com a hierarquia, pois ser livre significa "ser isento da desigualdade presente no ato de comandar, e mover-se numa esfera onde não [existe] governo nem governados".

Nos termos de Arendt, a mera existência de relações de obrigação entre os membros do governo Kubitschek compromete o sentido político das suas ações. Não obstante, restam dúvidas se a administração paralela funciona de fato na base do cumprimento de ordens. Os relatos sugerem uma imagem diferente: trata-se de grupos temporários criados para suprimir a diferença entre superiores e subordinados, tendo em vista um compromisso comum com aquilo que os interessa, a saber, a efetivação do plano. Se confirmada essa hipótese, a administração paralela representa um espaço de exceção dentro da estrutura vertical do governo. Nesse espaço, os agentes experimentam conjuntamente a ampliação do seu horizonte de possibilidades, dentro do qual cabe finalmente aquilo que fora planejado. 


\section{Considerações finais}

Dependendo da concepção de "design" adotada, abrem-se ou encerram-se possibilidades teóricas de análise e proposição. Entendido como um processo e não como uma ferramenta, o design representa um campo amplo de investigação do modo como uma pluralidade de agente é capaz de transformar o presente estado de coisas. O caso do Plano de Metas do governo Juscelino Kubitschek destaca a atuação decisiva de grupos de agentes na efetivação das promessas de campanha. Impera no interior da chamada "administração paralela" um espírito de colaboração, possibilitado pelo abrandamento das divisões hierárquicas. $\mathrm{O}$ fundamental, contudo, é a emergência a partir daí de uma situação de projeto, na qual os agentes atuam conjuntamente. Essa situação sustenta o desenrolar do processo de projeto, isto é, a execução e a revisão constante do plano.

A questão da dimensão política do design liga-se ao problema das formas democráticas de participação política. No entanto, dependendo também da concepção de "político" adotada, abrem-se ou encerram-se possibilidades teóricas de análise e proposição. O exemplo da administração paralela do governo Kubitschek torna patente a existência de um círculo, mais ou menos definido, que separa os que estão dentro e os que estão fora do projeto. Ainda que imagem do círculo pareça incompatível com uma certa noção de democracia, não está eliminada a possibilidade de que as relações no interior desse círculo sejam políticas, no sentido derivado da teoria de Hannah Arendt. Com esse termo queremos evidenciar: 1) o encontro de agentes com visões, poderes e interesses diversos em um projeto comum; 2) o estabelecimento de laços interpessoais necessários à efetivação do projeto; e 3) a emergência de uma situação de projeto, na qual as suas ações têm efeito e sentido. Esses três aspectos marcam aquilo que entendemos como a dimensão política do projetar. Finalmente, como um processo intrinsecamente político, o design pode contribuir decisivamente para o enfrentamento dos "grandes desafios da humanidade". A própria de ideia de "projeto" supõe de início que seja possível mudar o status quo. Assim, a transdisciplina do design pode tornar-se um fazer e um saber dos modos de produzir deliberadamente um futuro diferente do presente. E no coração desse saber-e-fazer encontra-se um estudo da natureza e do funcionamento de grupos de agentes, articulados em torno de um problema comum.

\section{Notas}

1. As traduções das citações em língua estrangeira são todas do autor. Neste artigo, "design" é traduzido como "projeto" ou "projetar" sempre que tal sentido torna-se proeminente.

2. Assim como Victor Papanek, Tony Fry considera o design praticado por uma "miríade" de outros profissionais "que, consciente ou inconscientemente, toma decisões de projeto" (Fry, 2011, "Preface"). Mas ele relativiza o papel político dos designers ao afirmar que "ações focadas no design, na política e no político não implicam exclusividade - claramente há outros campos da conduta humana que deveriam ser vistos como uma contribuição àquelas transformações tão desesperadamente necessárias" (Ibid., "Introduction”). 
3. The Conference on Systematic and Intuitive Methods in Engineering, Industrial Design, Architecture and Communication é o nome do evento (Cross, 1984).

4. Lucas Lopes faz uma crítica à "ministerização" da função de planejamento, considerando-a parte constitutiva do Executivo: "Na verdade, o Ministério do Planejamento é uma pasta muito difícil de ser exercida por quem quer que seja. Ao menos, tem sido uma desgraça para quase todos os ministros, que passam lá algum tempo e nunca conseguem fazer muita coisa. [...] A ideia de Ministério do Planejamento me parece um pouco distorcida. Tem que existir junto ao presidente da República um órgão de cúpula, que tome decisões fundamentais e dê orientação geral, mas não sei se seria um Ministério do Planejamento" (Lopes, 1991, p. 171).

5. Lucas Lopes lamenta: "Pecamos muito em não ter um escritor ao nosso lado, escrevendo dia-a-dia o que se estava fazendo" (Lopes, 1991, p. 175).

\section{Bibliográfia}

Arendt, H. (2001). A condição humana (1958). Trad. Roberto Raposo. 10a ed. Rio de Janeiro: Forense Universitária.

Aristóteles. (2005). Retórica. Trad. Manuel Alexandre Júnior, Paulo Farmhouse Alberto \& Abel do Nascimento Pena. 2a ed. Lisboa: Centro de Filosofia da Universidade de Lisboa; Imprensa Nacional-Casa da Moeda. (Obras completas de Aristóteles, vol. VIII, Tomo I)

Benevides, M. V. de M. (1979). O governo Kubitschek: desenvolvimento econômico e estabilidade política, 1956-1961 (1976). 3a ed. Rio de Janeiro: Paz e Terra. (Coleção Estudos Brasileiros, Vol. 8)

Boland, R. \& Collopy, F. (2004). Managing as designing. Stanford California: Stanford Business Books.

Bonsiepe, G. (2011). Design, cultura e sociedade. São Paulo: Blucher.

Bonsiepe, G. (2012). Design como prática de projeto. São Paulo: Blucher.

Buchanan, R. (1989). "Declaration by Design: Rhetoric, Argument, and Demonstration in Design Pratice" (1985). In Victor Margolin (ed.). Design Discourse: History, Theory, Criticism. Chicago: University of Chicago Press.

Buchanan, R. (1995). "Rhetoric, Humanism, and Design". In Richard Buchanan e Victor Margolin, (eds.). Discovering Design: Explorations in Design Studies. Chicago: University of Chicago Press.

Buchanan, R. (1999). "The Study of Design: Doctoral Education and Research in a New Field of Inquiry". In Doctoral Education in Design: Proceedings of the Ohio Conference (1998). Pittsburgh: Carnegie Mellon University.

Buchanan, R. (2005). "Design As Inquiry: The Common, Future and Current Ground of Design". In John Redmond et al. FutureGround: Proceedings of the International Conference of the Design Research Society. Melbourne: Monash University.

Campos, R. (1994). A lanterna na popa: memórias. 2a ed. Rio de Janeiro: Topbooks. Cross, N. (ed.). (1984). Developments in Design Methodology. Chichester, New York: Wiley. Dewey, J. (1938). Logic: The Theory of Inquiry. New York: Henry Holt and Company. 
Fry, T. (2011). Design as politics. Oxford; New York: Berg.

Junginger, S. \& Faust, J. (2016). Designing business and management. London; New York: Bloomsbury Academy.

Kuttner, R. (2018). Can Democracy Survive Global Capitalism? New York; London: W. W. Norton \& Company.

Lafer, C. (2002). JK e o Programa de Metas (1956-61): o processo de planejamento e o sistema político no Brasil (1970). Trad. Maria Victoria de M. Benevides. Rio de Janeiro: Editora FGV.

Lafer, C. (2003). “O planejamento no Brasil - Observações sobre o plano de metas (19561961)”. In Betty Mindlin (org.). Planejamento no Brasil. 5a ed. São Paulo: Perspectiva.

Levitsky, S. \& Ziblatt, D. (2018). How Democracies Die. New York: Crown.

Lindinger, H. (1991). Ulm Design: The Morality of Objects (1987). Cambridge, Massachusetts: The MIT Press.

Lopes, L. (1991). Memórias do desenvolvimento. Rio de Janeiro: Centro da Memória da Eletricidade no Brasil. (Programa de História Oral do CPDOC/FGV)

Papanek, V. (1985). Design for the Real World: Human Ecology and Social Change (1971). 2a ed. Chicago: Academy Chicago Publishers.

Rittel, H. (2010a). "On the Planning Crisis: Systems Analysis of the First and Second Generations” (1972). In Jean-Pierre Protzen e David J. Harris (orgs.). The Universe of Design: Horst Rittel's Theories of Design and Planning. New York: Routledge.

Rittel, H. (2010b). “The Reasoning of Designers” (1988). In Jean-Pierre Protzen e David J. Harris (orgs.). The Universe of Design: Horst Rittel's Theories of Design and Planning. New York: Routledge.

Runciman, D. (2018). How Democracy Ends. London: Profile Books.

Simon, H. (1996). The Sciences of the Artificial (1969). $3^{\text {a }}$ ed. Cambridge: Massachusetts: The MIT Press.

Resumen: En las discusiones sobre diseño y política, el diseño es visto generalmente como un instrumento de la política. En este sentido, el diseño está sometido a intereses ajenos, sean ellos democráticos o no. Pero para que se revele su dimensión política más propia, es hace necesaria otra concepción del diseño. En este artículo, siguiendo las teorías acumuladas desde los años 1960, el diseño es pensado como un proceso. Como designing, es practicado no sólo por diseñadores profesionales, sino por un conjunto de agentes, con responsabilidades y capacidades diversas. Estos agentes convergen en torno a un problema, generando a una situación de proyecto, fundamental para el proceso de diseño. Por el modo como esa situación articula a los agentes en torno a la producción de un futuro común, es revelado su carácter eminentemente político. El Plan de Metas del gobierno brasileño entre 1956 y 1961 presenta un caso excepcional de situación de proyecto, pues reordena agentes públicos y privados en una administración paralela con el propósito de hacer efectivo el Plan. Contorneando la oposición del status quo político y la burocracia del Estado, la estrategia organizacional de Juscelino Kubitschek hace possible el cumpli- 
miento de las promesas de campaña en pro del desarrollo nacional. En fin, el estudio de este caso, bajo una renovada perspectiva teórica, refuerza la existencia de un campo del saber-y-hacer del diseño.

Palabras clave: Teoría del diseño - Planificación - Teoría organizacional -Administración - Historia política - Brasil.

\begin{abstract}
In debates about design and politics, design generally appears as an instrument of politics. In this sense, design is subordinated to alien interests, be they democratic or not. Therefore, in order to reveal its own political dimension, another conception of design is necessary. In this article, following the theories accumulated since the 1960s, design is considered as a process. As designing, it is practised not only by professional designers, but by a set of agents, with diverse responsibilities and capacities. These agents converge around a problem and give rise to a design situation, fundamental to the design process. The way the design situation articulates agents toward the production of a common future reveals its eminently political nature. The Brazilian government's Target Plan between 1956 and 1961 presents an excepcional case of a design situation, in that it reorganizes public and private agents into a parallel administration with the aim of effecting the Plan. Bypassing the opposition from the political status quo and the state bureaucracy, Juscelino Kubitschek's organizational strategy makes it possible, in fact, to fulfill his campaign promisses in favor of national development. Finally, the study of this case from a renewed theoretical perspective reinforces the existence of a design field of knowing-and-doing.
\end{abstract}

Keywords: Design theory - Designing - Organizational theory - Management. - Political history - Brazil.

[Las traducciones de los abstracts fueron supervisadas por el autor de cada artículo] 